\title{
Digital Government Strategies for Sustainable Development: A Case Study of Pakistan
}

\author{
M. Irfanullah Arfeen ${ }^{1}$, Firstname Lastname ${ }^{2}$ and Firstname Lastname $2, *$ \\ 1 QASMS, Quaid-i-Azam University, Islamabad, Pakistan; m.arfeen@qau.edu.pk \\ 2 Affiliation 2; e-mail@e-mail.com \\ * Correspondence: e-mail@e-mail.com; Tel.: (optional; include country code; if there are multiple correspond- \\ ing authors, add author initials)
}

\begin{abstract}
The research study examines the Digital government strategies of different countries and compare it with the Digital Pakistan Policy 2018. Different countries focus on the different factors/themes as per requirement of their countries and need of their citizens. Therefore, a requirement for research that compares the different digital government strategies has been identified. Secondary data on eGovernment strategies of different governments have been examined to investigate best practices in other countries. The qualitative data analysis software program NVivo has been used to facilitate code-based analysis of different digital government strategies. The findings and recommendations can be successfully utilized for the improvement of digital government strategies and its alignment with Sustainable Development Goals (SDGs) 2030.
\end{abstract}

Keywords: Citizens; Digital; Development; eGovernment; Strategy; Sustainable

\section{Introduction}

A digital government strategy becomes a fundamental element in modernizing the public sector, through identifying and developing organizational structure, the ways of interactions with citizens and business, and reducing cost and layers of organizational business processes [1]. Many governments are implementing digital government projects without having proper digital government strategy or they have the strategy but it's not addressing their ground realities. Thus, they are losing millions of euros because of the projects failures and becoming a very burning issue.

This study examines the eGovernment strategies of different countries and their alignment with SDGs. This study also analyzes the IT Policy, eGovernment Strategy and Digital Pakistan Policy of the Government of Pakistan.

\subsection{Research Question}

The research question is:

RQ1. What are the practices prevailing in eGovernment strategy for achieving SDGs in Pakistan at national and municipal level?

\section{Literature Review}

Under digital government strategy, government agencies will be able to transform from a tradition government to digital government and reform the organizational structure. Nowadays, digital government includes all ICT to support inter-government operations and activities, focus onto citizens, and public services delivery to all parts of the community. For this purpose, holistic approach adopted to develop digital government ecosystem which includes all themes like e-court, e-banking, e-participation, e-procurement, e-services, e-transformation, e-waste, e-Learning, e-health and smart cities, etc.

Thus, this research examines the digital Pakistan strategy [2] and presents the themes which other countries included in their Digital Government Strategies (see Table 1). 
Table 1. Digital Government Themes

Themes
e-Court

e-Energy

e-Banking

e-Participation

e-Procurement

e-Services

e-Transformation

e-Waste

e-Learning/

Education

e-Health

e-Passport
Description

Court using e-files and e-orders. ICT for administration of Justice to reduce delay, provide efficient case management and equitable access to obtain court orders.

Use of wireless smart metering system for billing.

Banking through the Internet, all transaction and bill payments perform through banks websites

Online consultation/ dialogue/ Deliberation of the decision-making and policy formulation process. Redress grievances at grassroots level.

Purchasing of goods and services through internet.

Public Service Delivery through the use of ICT to all segments

Process of transforming into an innovative and effective IT-enabled service provider

Digital hardware uses large amounts of raw materials in its manufacture, can contain toxic substances, tends to have a short lifespan and is often not recyclable. This has created an international e-waste problem.

- Using ICT to provide education at students' doorsteps

Combine use of health resources and ICT for health care and other services related to health. Monitors patients in their own homes. Provides Electronic Health Records.

Smart card preservers the features of the current passport in the identification of its holder in contactless chip.

\section{Countries}

Central African Republic, Croatia, Ethiopia, India, Korea, Liberia, Malaysia and Portugal

Estonia and Pakistan

Albania, Armenia, Australia, Bahrain, Bangladesh, Bhutan, Cambodia, Cape Verde, Chile, China, Congo, Denmark......

Albania, Bahrain, Bangladesh, Barbados, Belarus, Belgium, BiH, Brazil, Cambodia, Cameroon, Canada......

Albania, Argentina, Armenia, Austria, Bangladesh, Belgium, Bhutan, BiH, Cambodia, Cameroon, Cape Verde......

Albania, Argentina, Austria, Bahrain, Bangladesh, Barbados, Belarus, Belgium...

Albania, Armenia, Australia, Austria, Bahrain, Bangladesh..

Bhutan and New Zealand

Albania, Argentina, Austria, Bahrain, Bangladesh...

Albania, Argentina, Armenia, Australia, Austria, Bangladesh, Belarus, Belgium, BiH, Botswana, Bulgaria, Cambodia...

Botswana, Brunei, Cape Verde, Chile, Costa Rica, Croatia, Estonia, Ethiopia, France, Gabon, India, Iraq, Ireland, Lesotho, Liberia, Lithuania, Luxembourg, Malawi 
e-Payment

e-Leadership

e-Tourism

e-PO Box

e-Pension

e-Strategy

e-Readiness

e-Employment

e-Agriculture
Citizens make many different kinds of payment through the internet to the government.

Local e-Leaders who drives eGovernment initiatives and support eGovernment diffusion.

Establishment of the tourism portal and provide free internet at tourist areas.

Government portal provides private account to the citizens and businesses for their pension record, social security and a wide range of other services.

Improvement of the level of service quality, mainly achieved through greater flexibility (24/7 service availability, multi-channel service delivery etc.), customization and transparency.

Develop the ICT integration in a country

Readiness in human capacities, political leadership, institutional frameworks, supportive policies, complimentary regulations, business environment, investment opportunities, and public-private partnerships in technologies.

Covers e-recruitment procedures for the public service.

Use of mobile and internet by farmers to obtain information on the latest prices of their produce.
Bahrain, Bhutan, BiH, Croatia, Dominican Republic, Georgia, Egypt, Ethiopia, Germany, Grenada, Hungary..

Brunei, Colombia, Cyprus, Czech Republic, Egypt, Estonia, Ethopiia, Ghana, Greece, Hungary, India, Indonesia, Iran, Jordan, Korea, Kyrgyzstan, Libya, Luxembourg, Malawi

Albania, Cambodia, Chile, Cyprus, Georgia, Egypt, Ethiopia, Ghana, Hungary, India, Jamaica, Jordan, Lebanon, Malawi, Namibia, Oman and Slovak Republic

Japan

Croatia, India, Italy and Kenya

Bhutan, Cape Verde, Central Africa, Chile....

Bahrain, Bangladesh, Barbados, Belarus, Bhutan, Botswana, Bulgaria, Cambodia, Cameroon, Cape Verde, Chile, Congo, Costa Rica, Croatia, Cyprus.....

Albania, Cameroon, Cape Verde, Costa Rica, Croatia, Egypt, Ethiopia, Fiji, Latvia, Lithuania Bulgaria, Cameroon, Central Africa, Costa Rica, Egypt, Ethiopia, Fiji, Finland, Ghana, India, Jamaica, Kenya, Latvia, Liberia, Lithuania, Madagascar, Mauritius, Namibia, Pakistan 


$\begin{array}{ll}\text { e-Culture } & \text { ICT is used in cultural and natural resources } \\ \text { preservation } & \\ \text { e-Work } & \text { Work from the home to using ICT connected } \\ & \text { with the employers' network, multi-locational } \\ & \text { working and to relocate work to remote offices } \\ \text { Purchasing products and services online, also } & \text { known as online shopping } \\ \text { e-Shopping } & \text { People, community and civil society are getting } \\ \text { training on digital literacy. } & \\ \text { e-Society } & \text { Use of ICT in order to improve democratic } \\ \text { process and political representation. } & \text { Enabler towards achieving good governance } \\ \text { e-Democracy } & \text { while increasing the ability of citizens to access } \\ \text { e-Governance } & \text { public service via internet } \\ \text { Entertainment that someone is able to see or } \\ \text { hear using the internet. } \\ \text { e-Entertainment }\end{array}$

Bulgaria, Cameroon, Costa Rica, Cyprus, Georgia, Egypt, Hungary, Kazakhstan, Lithuania, Nepal, Slovak Republic, Trinidad Costa Rica, Egypt, Japan, Korea and Mauritius

Ghana, Japan and South Korea

Argentina, Belgium, Bhutan, Cambodia, Cameroon, Congo, Cyprus, Dominican Republic.. Argentina, Austria, BiH, Brazil, Bulgaria, Cameroon...

Afghanistan, Brunei, Jordan, Pakistan and Portugal.

Croatia, Egypt and Fiji

Central Africa, Costa Rica, Egypt, El Salvador, Ethiopia, Greece, Hungary, Latvia, Lithuania. Cameroon, Georgia and Jordan

Many concepts/themes are used in digital government documents such as e-architecture, e-channel, e-concessions, e-book, e-Deliberation, e-petitions, e-initiative, e-Post, efacility, e-policy, e-session, e-solutions, e-decision, e-consultation, e-licenses, e-registration, e-skills, e-transparency, e-forum, e-courses, e-usage,

e-journal, e-gate, e-immigration, e-Mincom (e-Ministry of Communication), e-documentation, e-Submission, e-civil service, e-ASEAN Task Force, e-ASEAN Framework Agreement, e-trade, e-orientation, e-inclusion, e-voting, e-accounting, e-catalog, e-communication center, e-complaints, e-building, e-police, e-gates, e-return, e-transactions, enewsletters, e-laws, e-processes, e-medicine, e-literacy, e-record, e-censorship, e-championship, e-schools, e-schooling, e-retail, e-visas, e-network, e-regulations, e-safety, e-development, e-innovation, e-challenges, e-Barometer, e-

Knowledge, e-auditing, e-monitoring, e-debt, e-budget, e-human, e-archive, e-people, e-opinion, e-information, e-resilience, e-form, e-notification, e application, e-environment, e-index, e-bay, e-enabled, e-portal, e-certificate, e-training, e-manifest, e-Sustainability, e-permitting, e-Statistics, e-literate, e-community, e-vision, e-Sign, e-Minister, eChampions, e-objectives, e-cities, e-local, e-Mentorship, e-land, e-tools, e-survey, e-logistic, e-discussions, e-digital.

In Bangladesh, Ministry of Commerce has provided online price monitoring system for farmers and offers daily price updates in its websites. However, usage of this information is not significant. In Barbados, Internet security education is essential for 
government officials and they know about security pitfalls. Constant security awareness is essential to improve government culture. Pakistan digital policy focus on ICT education, e-learning for the educational as well as other strategic sectors and lifelong learning process for all in line with Sustainable Development Goals (SDGs) of the United Nations. In Dubai, the eGovernment program has adopted a comprehensive strategy of e-Transformation, based on concepts of modernization and development by offering e-Services with full integration, which depends on technology as a driving force behind eGovernment.

Federal Ministry of IT, Government of Pakistan, formulated its first IT Policy and Action Plan in 2000. After that in 2002 government established the Electronic Government Directorate (EGD) to launch many eGovernment projects. In 2005, eGovernment Strategy and 5-year plan for the federal government was developed. Abridged eGovernment Strategy of Pakistan has been formulated in 2012. Recently, Ministry of IT prepared a draft of Digital Pakistan Policy 2017 which is available on the Ministry of IT website: http://moit.gov.pk (see Figure 1).

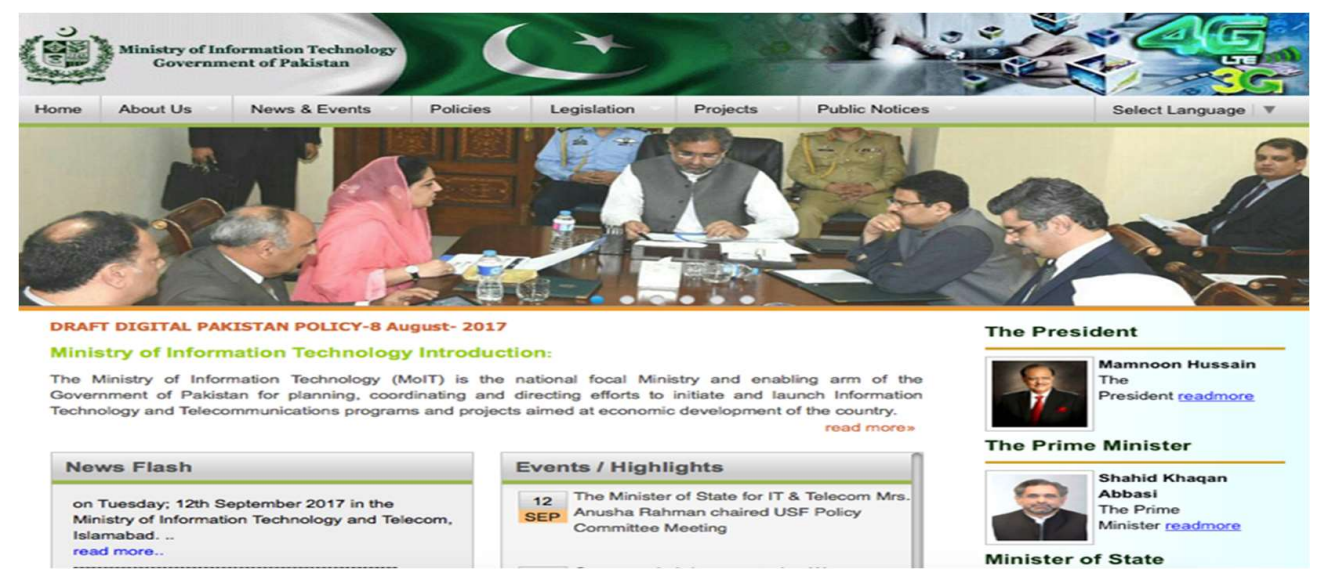

Figure 1. Website of the Ministry of IT having Draft Digital Pakistan Policy 2017

Still, there is a dire need to conduct more focused research on eGovernment practices and problems embedded in the execution of eGovernment strategy in Pakistan. The purpose of this research is to see that how can current eGovernment practice be interpreted from a development perspective in Pakistan at national and municipal level. Developed countries have resources to implement their eGovernment strategy whereas developing country like Pakistan is facing many hurdles in eGovernment strategy execution because of lack of resources, electricity shortfall, and other issues.

\section{Research Design}

The main objective in this study is to discover the similarities of eGovernment strategies of different countries. Few relevant available reports are selected based on convenience sampling. Then, coding process and content analysis approach will be utilized in text via NVivo software. The empirical part of this study comprises of an inductive, secondary data case study, which is suitable for the purpose of achieving a deepened understanding of eGovernment strategy for sustainable development. eGovernment studies of other countries were chosen as the main method for data collection in the case study are heterogeneous, hence flexibility and scoping will be needed. This study will provide the code-based analysis and content analysis of eGovernment strategies, three level policy analysis and emerging trends in eGovernment Strategy. 


\section{Coding Analysis}

A code-based analysis has been conducted through NVivo software to observe trends in eGovernment Strategy of different countries.

Once the coding process was started, word count and frequency of occurrence were analyzed and exported from the NVivo 12 plus software and continued the analyses of emerging concepts from the data generated using the word frequency tool in NVivo. The main finding of this study suggests the eGovernment strategy reports of different governments are focusing on citizens during formulation time. Figures 3 shows that the term like citizens, electronic, eGovernment, online, strategy and portal are used maximum times in these reports. On the other hand, few words like entities, broadband, skills and telecommunications were used very less in different countries reports. This represents citizens are most important for the success of their projects. However, eGovernment failures shows that they are not taking on-board citizens during execution time.

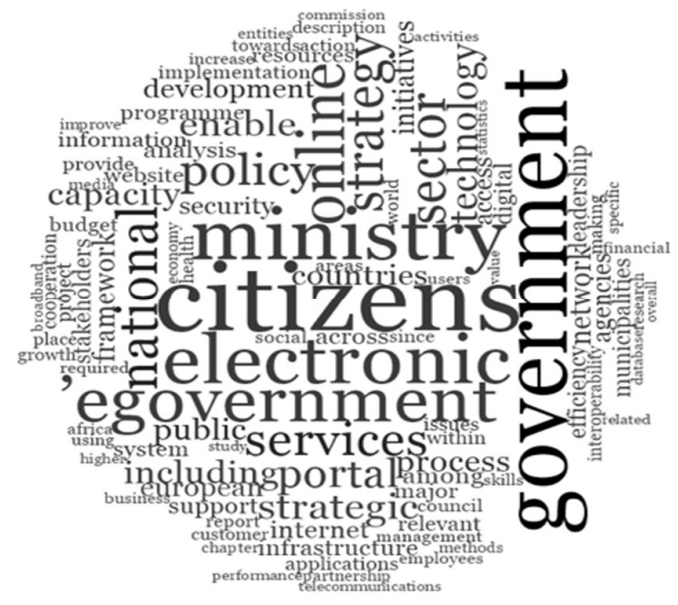

Figure 3. Word Cloud- show the importance of citizens from the eGovernment Strategies of different countries

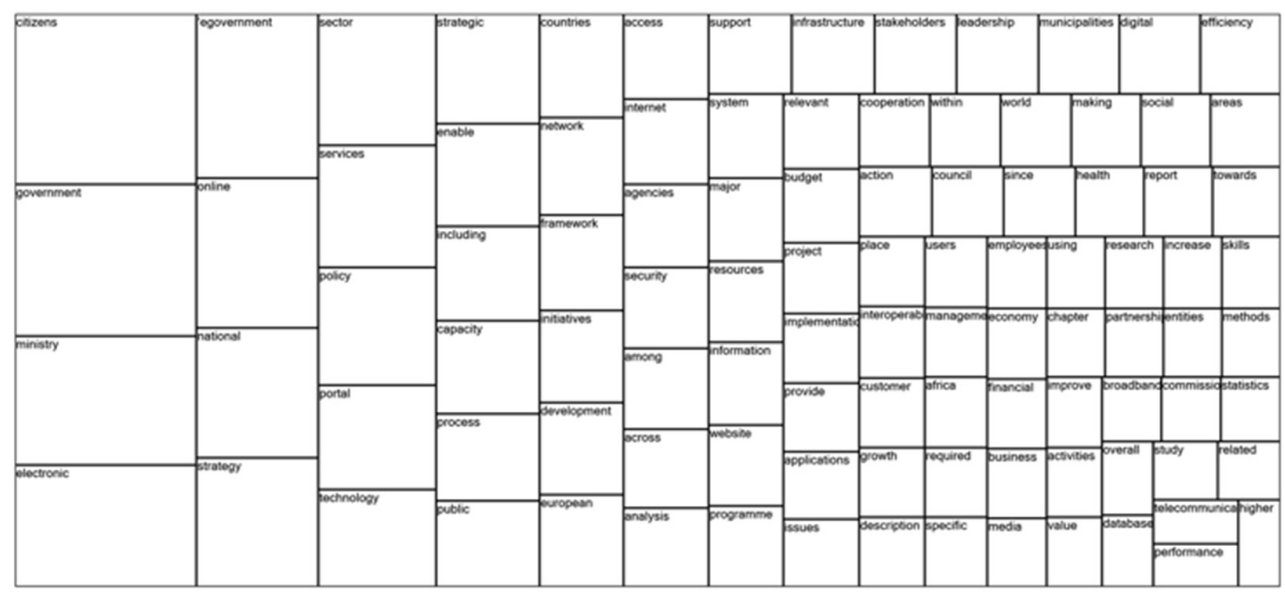

Figure 4. Hierarchy Chart of eGovernment Strategies of different countries

Figure 4 shows the hierarchy chart of the concepts presented in eGovernment Strategies of different countries. In the Figure 4 citizens square area represents the maximum number of coding at the node. However, database, telecommunication and performance 
in the above figure right hand side smaller area of covered by the nodes, shows the smaller number of coding at the node.

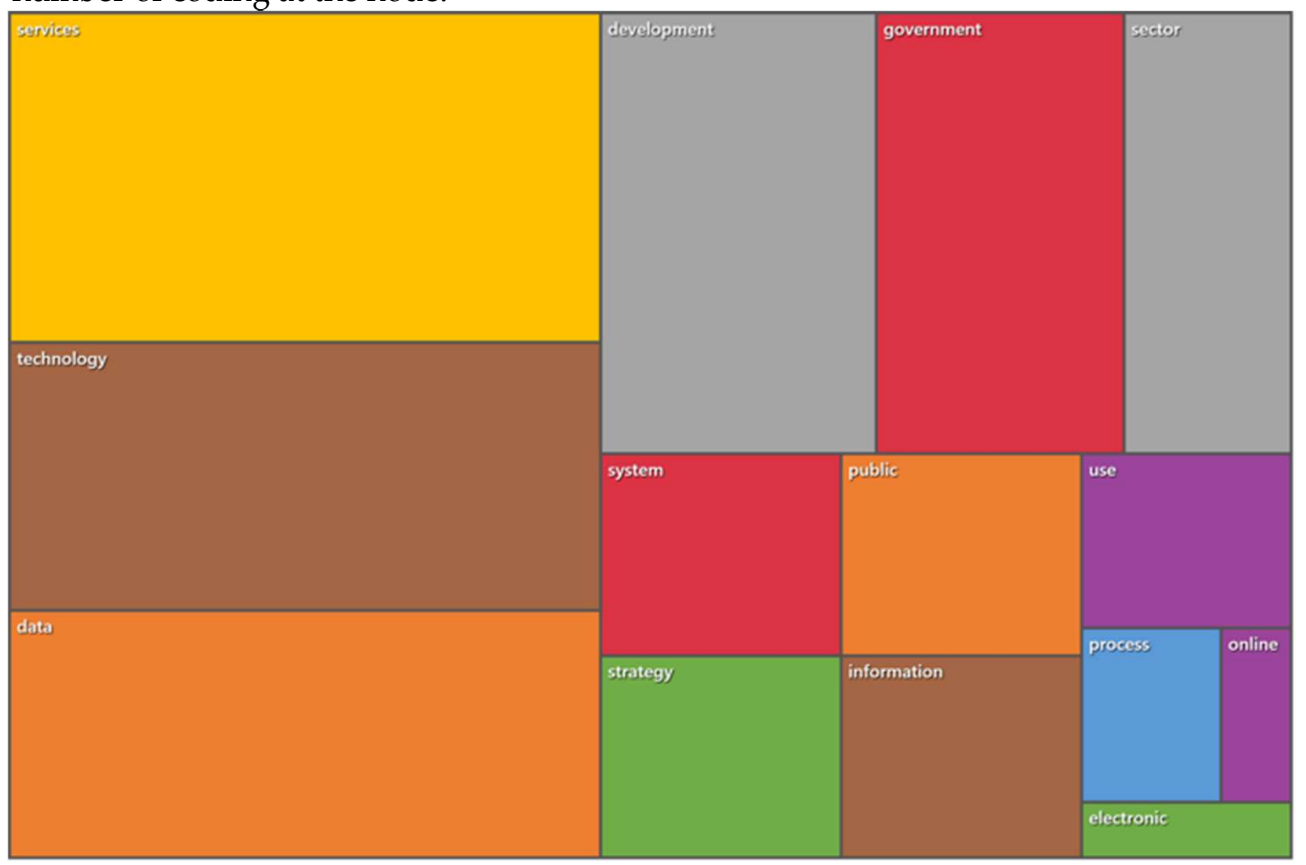

Figure 5. Hierarchy Chart of Digital Pakistan Policy, eGovernment Strategy and IT Policy of Pakistan

Figures 5 \& 6 show the hierarchy chart of the concepts presented in IT Policy of Pakistan, eGovernment Strategy and Digital Pakistan Policy reports. In Figure 4 services square area represents the maximum number of coding at the node. However, right hand side smaller area of covered by the nodes, shows the smaller number of coding at the node.

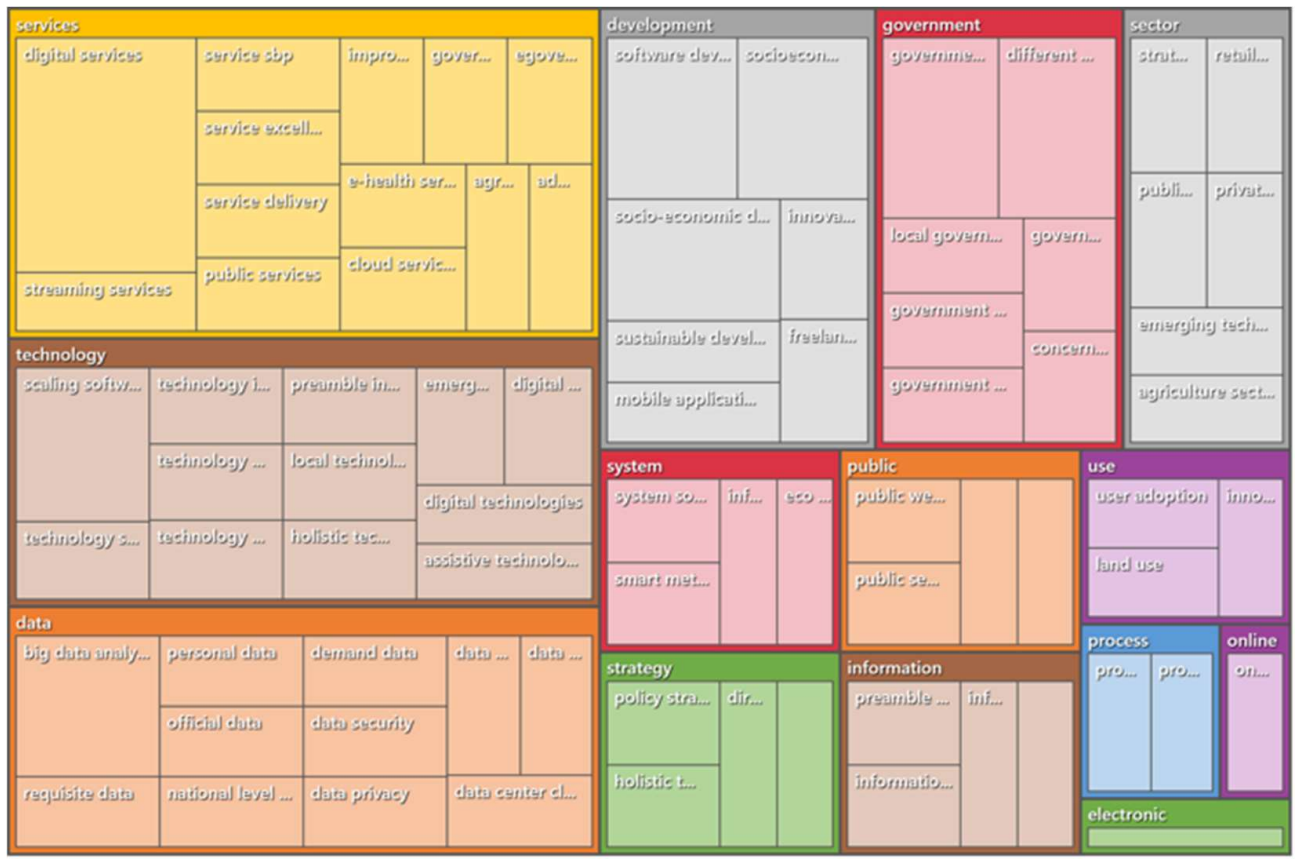

Figure 6. Hierarchy Chart of Digital Pakistan Policy, eGovernment Strategy and IT Policy of Pakistan 
It seems that government of Pakistan is good to provide digital government policy but failed in its implementation which has negative impact on eGovernment ranking. Digital government has been utilized to please the bosses instead of address the various real issues face by the citizens. On papers government is achieving all milestones whereas reality is totally different. eGovernment roadman 2016-20 provided by the government to achieve SDGs as set by the UN (see figure 7). Nevertheless, the government not only set timelines to reach goals but try to take onboard citizens and achieve it on time.

It seems that government of Pakistan is good to provide digital government policy but failed in its implementation which has negative impact on eGovernment ranking.

Digital government has been utilized to please the bosses instead of address the various real issues face by the citizens. On papers government is achieving all milestones whereas reality is totally different. eGovernment roadmap 2016-20 provided by the government to achieve SDGs as set by the UN (see figure 7). Nevertheless, the government not only set timelines to reach goals but try to take onboard citizens and achieve it on time.

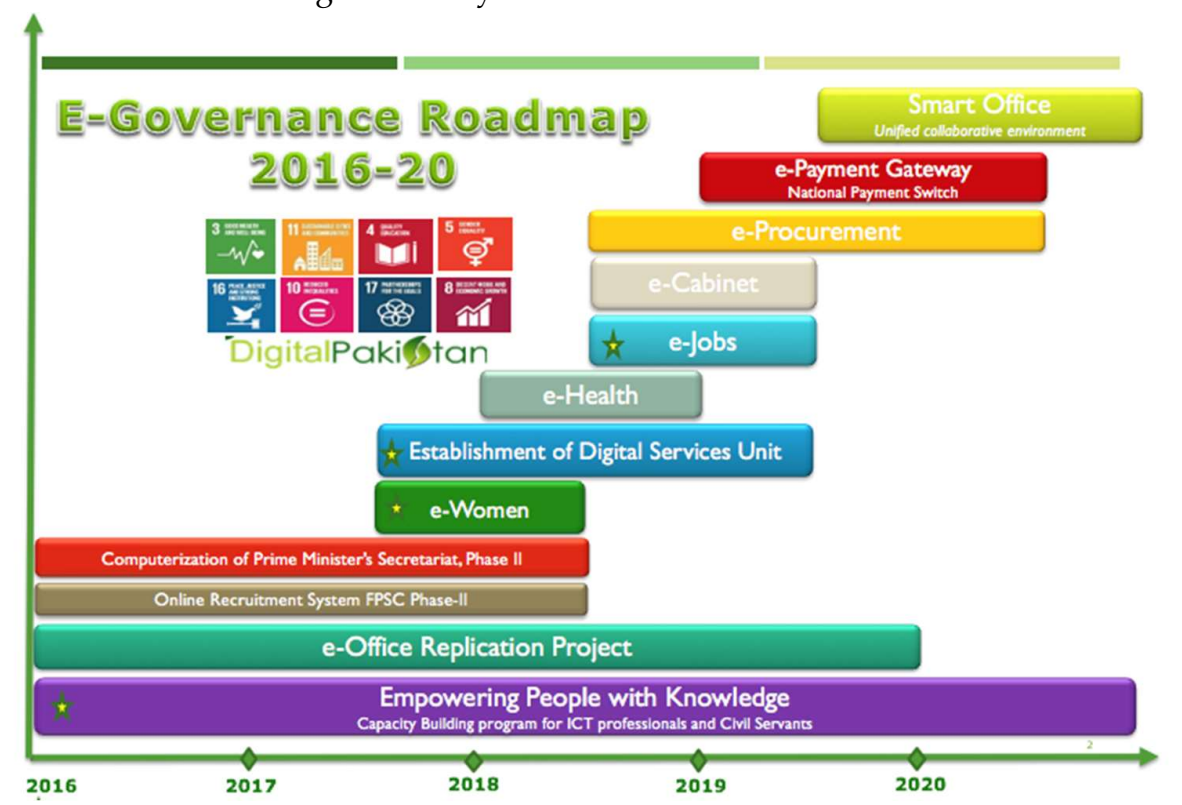

Figure 7. eGovernment Roadmap 2016 - 2020

\subsection{Digital Pakistan Future Plans}

To address the issues of sustainability, interactivity and standardization of eGovernment activities, NITB will be establishing the frameworks, policies, and standardization for:

IT Products/Services Procurement Framework

IT Advisory Framework

Enterprise Architect Framework

NITB will continue its efforts in providing technical expertise to federal government organizations in their process of revamping and strengthening core ICT infrastructure and resources, establishing citizen facing portals and application.

In 2017-18, NITB is going to initiate the following projects under eGovernment intiatives to facilitate citizens, businesses, and government organizations.

E-Health: Promote “One Patient - One ID" by providing all federal government administered hospitals with a central Patient Registration System; Outpatient \& 
Specialties/Consultant, In-Patient \& Emergency/Casualty, Operation Theatres, Intensive Care Unit (ICU), Diagnostic Information, Patient Billing \& Income, Medical Stores \& Pharmacy, Medical Record Management System; and Clinical Laboratory Module Provision of HR, Finance, Library, Helpdesk, Assets management system

E-Citizen: Portal for cross-agency citizen-centric government information and services. Provision (through development or integration of existing applications) of all basic citizen services through single portal and/or mobile app such as processes for getting Birth/Death Certificate, Domicile, CNIC, Weapon Registration, Driving license, records from Law Enforcement Agencies, Marriage Certificate/Marital Status, Passport, Income and property tax, Senior Citizen/Old age Benefits and so on.

E-Women (Baytee): Strengthening the existing 'ICT for Girls' initiative of MoITT by providing a cross platform app that can be used to provide single interface to urban and rural female community of Pakistan to have the access to following services:

Advocacy on Women Rights, Information on Laws, Rules \& Regulations,

Search

Academic Institutes, Schools, Colleges, and Universities

Scholarship opportunities for females

Career development and training opportunities for females

Jobs and internships opportunities (females preferred)

Health Care Services including Hospitals and Doctors for females

Lodging and hostel facilities for females

E-Jobs: Centralized portal to manage process of hiring - not covered by FPSC - from placement of job advertisement till selection of the right candidates in federal government ministries and department, profile management for job seekers and employers, maintaining job seekers database for future analysis.

Smart Office: Automation of business processes though providing unified communication platform that includes better and more secure enterprise collaboration, email/messaging services, VoIP based text, audio and video conferencing, paperless faxing facility, and content management system

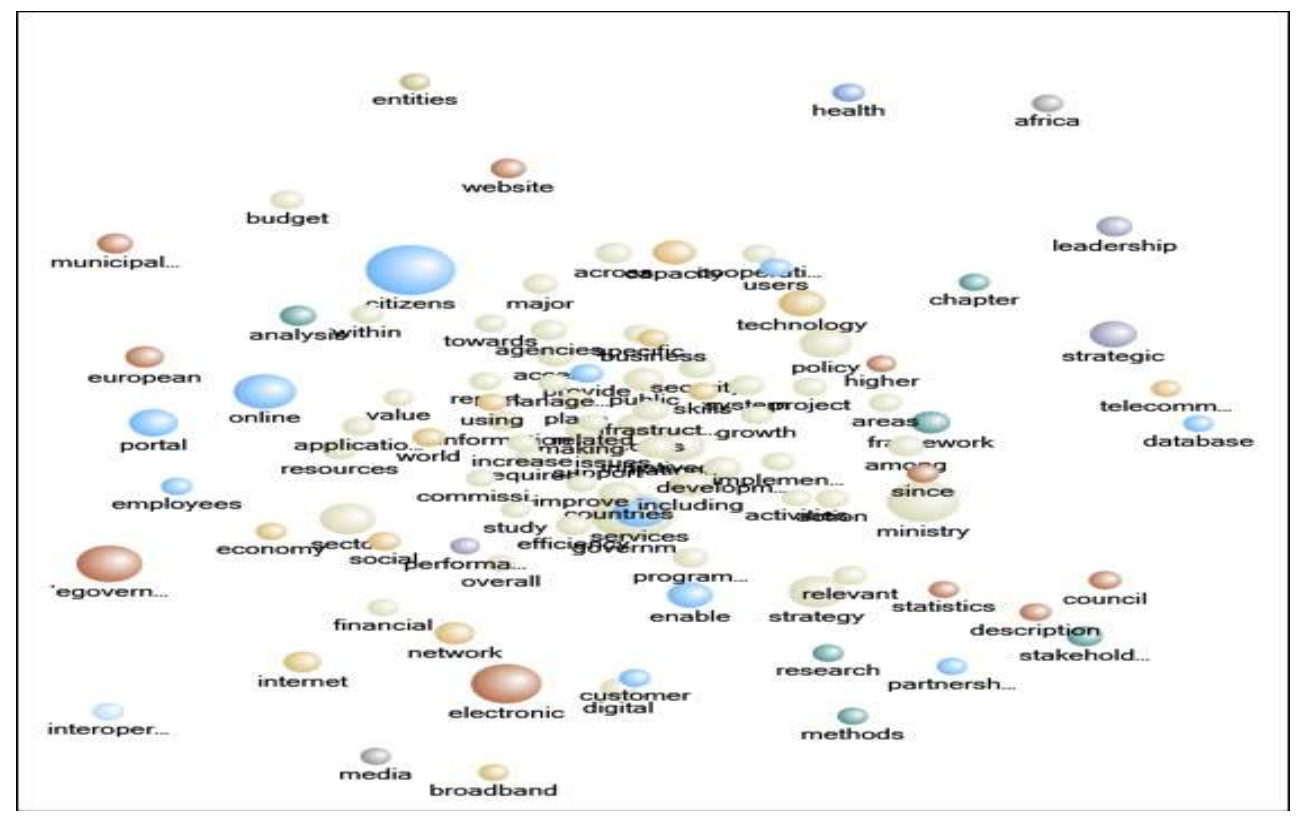

Figure 8. Cluster analysis of eGovernment Strategy of different countries. 
The cluster analysis of different countries strategies. With the size it shows the occurrence of different concepts in eGov strategies. It visualizes the occurrences of words and coded similarly by different nodes (see figure 8). Nevertheless, the citizens are mostly used word which shows their focus on citizen centric services.

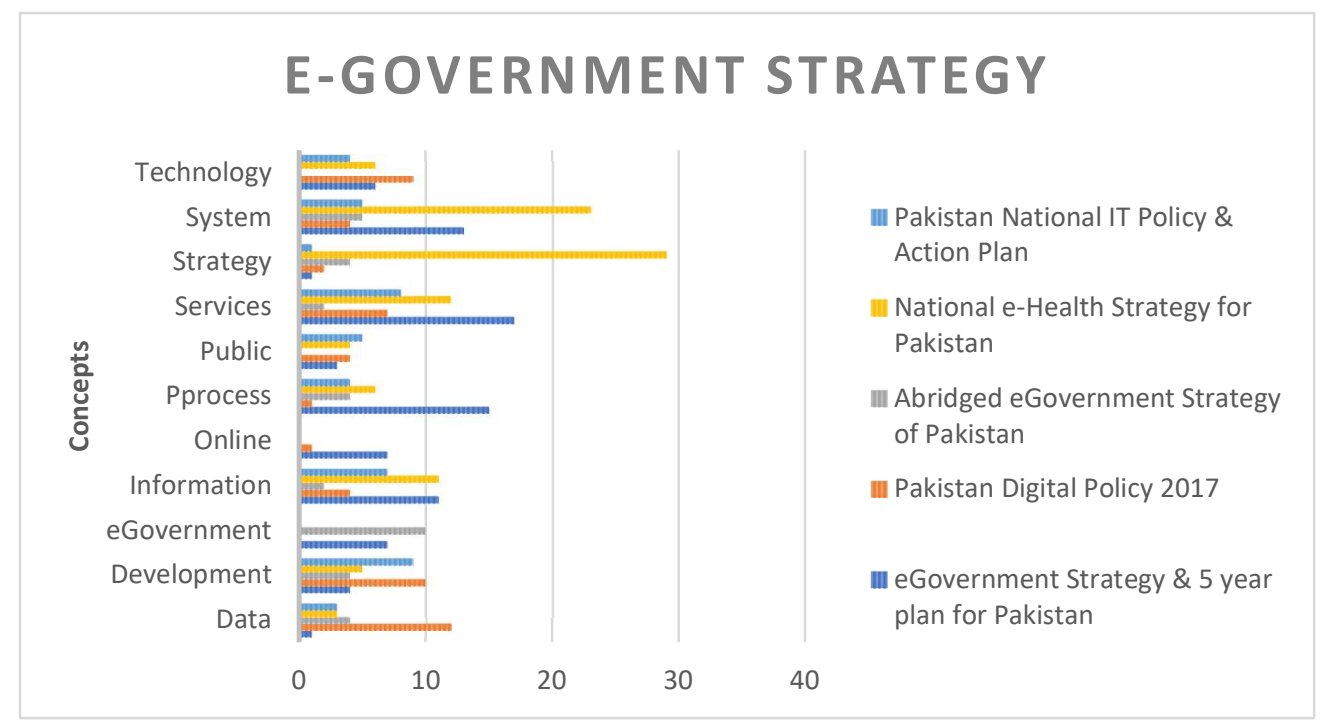

Figure 9. Concepts appearance in different eGovernment Strategies of Pakistan.

Figure 9 show the appearance of the concepts presented in IT Policy of Pakistan, National e-Health Strategy, Abridged eGovernment Strategy, Digital Pakistan Policy and eGovernment Strategy reports. In Figure 8 technology concept most of the time use by digital Pakistan Policy, eGovernment mostly use by the Abridged eGovernment Strategy. Data appears in every policy with most of occurrence in Pakistan Digital Policy.

\section{Recommendations}

There is a need to raise citizens awareness in relation to the dangers from cybercrime. Establishment of a portal for the awareness focusing on computer safety. Also, need to organize information and awareness seminars and workshops. There is need to increase take-up level with the use of effective marketing and relatively low cost of using the internet. Government can launch Facebook page and twitter account to interact with citizens through social network. Government can conduct survey to analyze most frequently used e-Services by the citizens. This kind of survey helps the government to improve its public access and trust. Government can use ICT to empower women and disadvantaged communities to provide them education so that it can improve their daily lives.

\section{Conclusions}

This study provided an in-depth evaluation of the eGovernment strategies. From the analysis of eGovernment strategies it is observed that citizens are most important factors for the success of any eGovernment initiatives. It is necessary for different countries to align its eGovernment Strategies with the SDGs 2030. Digital government can be considered as a tool to empower citizens and reduce poverty. Without its adoption, there is little chance to develop and empower citizens. Still, many digital government strategies lack an institutionalized commitment to gender equality and women empowerment.

Some countries eGovernment strategies of different countries some strategies are not available in English. There is a need to understand the barriers regarding the formulation 
and implementation of eGovernment strategies. Somehow, the data collected different reports about eGovernment strategies are of limited contribution to the debate about role of eGovernment strategies for sustainable development.

\section{References}

1. Nograšek, J. \& Vintar, M. eGovernment and organisational transformation of government: Black box revisited?. Government Information Quarterly, 31(1), 108-118 (2014).

2. Ministry of Information Technology and Telecommunication - MoITT, 24 March 2018, from http://moit.gov.pk/ (2017)

3. UNKB - Nations digital government Development Knowledge Base (2012), “digital government Survey 2012’, Department of Economic and Social Affairs, Division of Public Administration and Development Management, New York.

4. Yilmaz, R. (2017) 'Exploring the role of e-learning readiness on student satisfaction and motivation in flipped classroom', Computers in Human Behavior. Elsevier Ltd, 70, pp. 251-260. doi: 10.1016/j.chb.2016.12.085.

5. EGD, IT \& Telecom Division Government of Pakistan (2005), "e-Government Strategy and Five Year Plan of Federal Government of Pakistan 2005" Government of Pakistan, Islamabad.Author 1, A.B.; Author 2, C.D. Title of the article. Abbreviated Journal Name Year, Volume, page range.

6. IT \& Telecom Division (2000) “National IT Policy and Action Plan 2000” Government of Pakistan, Islamabad.

7. World Economic Forum. (2016). The global gender gap report 2016.

8. UNESCO (2016). ICT and the Information Economy: UNESCO Trains Women in E-Commerce.

9. UNKB - eGovernment Knowledge Database (2017), “United Nations eGovernment Survey 2016: eGovernment in Support of Sustainable Development', Department of Economic and Social Affairs, Division of Public Administration and Development Management, New York. Retrieved from https://publicadministration.un.org/egovkb/en-us/\#.Wb-ZDq3MxTY 